Revue

Revue de l'histoire des religions

del'histoire

des religions

$1 \mid 2020$

Varia

\title{
Daniel-Odon HUREL et Simon ICARD (dir.), La prière
} continuelle au XVII ${ }^{e}$ siècle. Exégèse, liturgie, mystique

Turnhout, Brepols ("Église, liturgie et société dans l'Europe moderne », 5), 2017

\section{Antoine Roullet}

\section{OpenEdition}

\section{Journals}

Édition électronique

URL : https://journals.openedition.org/rhr/10437

DOI : $10.4000 /$ rhr. 10437

ISSN : 2105-2573

Éditeur

Armand Colin

Édition imprimée

Date de publication : 1 mars 2020

Pagination : 155-158

ISBN : 978-2-200-93291-6

ISSN : 0035-1423

Référence électronique

Antoine Roullet, « Daniel-Odon Hurel et Simon ICARD (dir.), La prière continuelle au xvI" siècle. Exégèse, liturgie, mystique », Revue de l'histoire des religions [En ligne], 1 | 2020, mis en ligne le 01 janvier 2021 consulté le 05 janvier 2023. URL : http://journals.openedition.org/rhr/10437 ; DOI : https://doi.org/ $10.4000 /$ rhr. 10437

Ce document a été généré automatiquement le 5 janvier 2023

Tous droits réservés 


\section{Daniel-Odon HuREL et Simon ICARD (dir.), La prière continuelle au XVII ${ }^{e}$ siècle. Exégèse, liturgie, mystique}

Turnhout, Brepols («Église, liturgie et société dans l'Europe moderne », 5), 2017

\section{Antoine Roullet}

\section{RÉFÉRENCE}

Daniel-Odon HUREL et Simon ICARD (dir.), La prière continuelle au XVII siècle. Exégèse, liturgie, mystique, Turnhout, Brepols (« Église, liturgie et société dans l'Europe moderne », 5), 2017, $28 \mathrm{~cm}, 193$ p., ISBN 978-2-503-56573-6.

Cet ouvrage est issu d'une enquête lancée initialement par un spécialiste de Port-Royal, Philippe Sellier, dont les interrogations ont été élargies au XVII siècle français, sans aucune prétention à l'exhaustivité. L'enjeu est de revenir sur un thème dont Jacques Le Brun avait déjà souligné l'importance croissante, celui de la prière continuelle, en repartant de l'exégèse d'un verset très commenté de la première épître aux Thessaloniciens («Priez sans cesse », 1 Th 5, 17). L'ouvrage est organisé en deux parties, séparant des études ciblées sur tel ou tel auteur ou tel aspect des débats soulevés par cette injonction néotestamentaire $\mathrm{au} \mathrm{XvII}{ }^{\mathrm{e}}$ siècle dans le monde catholique et une anthologie de textes (assortis d'un appareil critique) qui constituent souvent les sources des études ouvrant le volume. On y retrouvera Cassien, Augustin, les deux autorités les plus citées sur la question, aux côtés de Cornelius a Lapide, Jean Hamon, Louis Thomassin, Fénelon, Bossuet et Jean Grancolas. Ces extraits ne sont pas de simples illustrations des idées déployées par les contributeurs de l'ouvrage, un réservoir d'exemples qui viendrait appuyer leurs démonstrations. Ils sont suffisamment longs et variés pour se faire une idée propre des enjeux du débat. L'ensemble constitue une proposition d'histoire intellectuelle très cohérente et les articles se répondent 
logiquement les uns aux autres dans une forme de progression qui n'est pas explicitée, mais qui présente d'abord l'héritage d'Augustin, Cassien et quelques autres grandes figures, avant de présenter leur relecture au XvII ${ }^{\mathrm{e}}$ siècle. L'objectif est d'historiciser ces textes et l'exégèse de ces versets à partir de l'anthropologie (au sens très large d'une conception de l'homme) qui sous-tend la prière. L'ouvrage tient pour l'essentiel ce pari proprement historiographique mené à partir de sources qui pourraient inciter à produire des textes plus théologiques et moins attentifs à contextualiser et à historiciser la question. Il est assorti d'une bibliographie précieuse, pour l'essentiel en français.

L'ouvrage construit son objet en autonomisant la question de la prière continuelle bien distinguée de débats connexes sur l'universalité de la prière ou sur le partage entre prière mentale et vocale. Ce choix est fécond car c'est lui qui met en évidence ce qui est présenté comme le cœur de la réflexion, à savoir le frottement entre une exigence biblique - «priez sans cesse»- et une nouvelle philosophie de l'acte, qui articule « disposition » et « acte ». Plutôt que d'insister sur les évolutions propres à l'histoire de l'exégèse, l'introduction de l'ouvrage et les différentes contributions montrent ce qui fait surgir la question de la prière continuelle comme un problème au XvII ${ }^{\mathrm{e}}$ siècle : avant tout, il s'agit de la recomposition d'une anthropologie puisque les manières de concevoir le rapport âme/corps, la structuration de l'esprit, le rapport entre acte et disposition en particulier, sont en train de se reconfigurer. Sur ce plan, la question de la prière continuelle est d'ailleurs associée aux débats sur la grâce. L'ouvrage explore donc l'espace et le va-et-vient entre l'héritage augustinien d'une prière pensée comme désir et la définition d'une prière comme acte - bénéfique, justifiable, qu'on peut offrir aux autres, mesurable, délimitée dans le temps et dans l'espace. Il est évident au $\mathrm{XVII}^{\mathrm{e}}$ siècle que l'idéal virtuose d'une prière enflammée et continue, assimilée à une hérésie via le contre-exemple mythique des Euchites, est une idée directrice, maximaliste mais irréaliste, qui impose que la prière, son rythme, sa liturgie, son organisation et son articulation avec les moments de la vie consacrés au sommeil, au travail, se fassent exégèses en acte du texte, et c'est la tension entre acte et disposition qui offre cette opportunité. Qu'il étudie des configurations liturgiques - l'adoration perpétuelle du Saint-Sacrement, devant lequel les religieuses se relaient - ou l'ordonnancement des heures et des exercices spirituels dévots qui se multiplient, l'ouvrage décrit des manières de fortifier une disposition qui s'épanouit dans des actes et qui est forgée par ces actes, selon un mécanisme d'auto-entretien qui est supposé être celui de la dévotion elle-même, comme acte de la volonté et disposition de l'esprit et du corps. En un sens, si l'ouvrage reste très ancré dans la tradition de «l'école française de spiritualité », il met en évidence, par le jeu des citations - Diego de Estella, Luis de Granada, Antonio de Alvarado, Giovanni Bona - à quel point le cloisonnement national ne tient pas dès qu'on touche à l'histoire de la spiritualité. Il reste que le $\mathrm{XVII}^{\mathrm{e}}$ siècle français structure l'ouvrage et appelle à un élargissement géographique et temporel du questionnement. L'articulation de la question avec d'autres débats antérieurs aurait aussi permis de remettre ces choses en perspective. La question de l'opportunité ou non de généraliser l'oraison mentale, soulevée au $\mathrm{XVI}^{\mathrm{e}}$ siècle en Espagne et en Italie, n'interpelle pas la continuité de la prière de la même manière que la querelle quiétiste sur laquelle l'ouvrage revient.

3 L'ouvrage appelle peut-être une contextualisation plus poussée de son interrogation très intellectuelle pour ne pas donner l'impression d'une histoire un peu hors-sol, qui 
ne concerne que les dévots les plus érudits, alors que derrière tous les problèmes soulevés, on trouve aussi une manière de réorganiser la société et d'interroger les rapports entre femmes et hommes ou clercs et laïcs. Tous ces questionnements ont comme point de fuite les manières de christianiser la société. L'exégèse de la prière continuelle doit déboucher sur une pastorale. C'est d'ailleurs un point qui affleure dans plusieurs textes, soucieux de souligner les implications ecclésiologiques de la question et l'articulation délicate, et non exempte de tensions, entre les exigences de la prière continue et la théologie des devoirs d'état dont on sait à quel point elle est caractéristique du temps. L'exigence de la prière continuelle n'est pas, contrairement à ce qu'on pourrait attendre, une préoccupation propre aux clercs : il n'est plus question de ramener la prière à une fonction sociale, comme on peut en avoir l'impression pour la prière médiévale, mais de penser une continuité de la prière qui dépasse l'organisation monastique et fonde une communauté de prière au-delà des devoirs d'état propre à chacun.

Une autre question est soulevée en creux par l'ouvrage, sans qu'il la prenne à bras-lecorps, celle du doute qui travaille de l'intérieur tout cet effort. La prière continuelle narre l'histoire de la réaction à ce qui est perçu comme une injonction contradictoire, une dissonance cognitive, une impossibilité radicale, stimulante, mais aussi inquiétante. La fragilité de l'édifice de la prière continuelle face au risque de la prière routinière ne rend pas justice aux efforts intellectuels déployés. On ne peut s'empêcher de penser aux contradictions du pari tridentin d'une mobilisation intégrale du dévot, qui insiste à la fois sur le déploiement des extériorités et des pompes de l'office et de la prière tout en affirmant le principe d'un accord profond des consciences à chacun des gestes de la prière. L'insistance de tous les manuels de prière tridentins sur la nécessité de prier avec "attention », " dévotion », la recherche d'une continuité de l'affect qui soutiennent la continuité des gestes, éclairent la question de la continuité de la prière et disent son revers, son contre-modèle, celui d'une prière froide, mécanique, réduite à ses extériorités. Sur ce plan, il aurait été intéressant de connaître l'exégèse protestante du même verset. Ce thème travaille le questionnement sur la continuité de la prière, notamment les textes bénédictins, dont la tradition est très tôt préoccupée par l'érosion de la qualité de la prière qui va avec sa multiplication et sa routinisation. La question n'est pas anodine car l'efficacité de la prière est conditionnée par sa qualité. Ces développements sur la prière continuelle doivent être confrontés à une histoire des techniques de la prière, de sa gestualité, dont le principe est précisément d'assurer la continuité d'une disposition intérieure toujours menacée qui est devenue, à l'époque moderne le " critère d'authenticité » de la prière, par un théâtre permanent et calculé de gestes, de proférations, de gémissements, etc. L'ouvrage s'en approche lorsqu'il travaille la frontière entre oraison mentale et vocale, lorsqu'il revient sur la respiration dévote que constituent les oraisons jaculatoires, lorsqu'il étudie le rythme et l'organisation des offices consécutifs comme des formes de réactualisation du désir et de la disposition dévote. De ce point de vue, la question de la prière continuelle irrigue toute une série de pratiques de compatibilité dévote ou de spiritualisation du quotidien - faire la vaisselle en méditant sur la purification du contenant et du contenu de l'âme, comme le proposent des carmélites du xVII ${ }^{\mathrm{e}}$ siècle - qui sont autant de techniques de production d'un temps dévot continu et dont les réflexions déployées dans cet ouvrage sont le pendant. 


\section{AUTEURS}

\section{ANTOINE ROULLET}

CNRS, Centre de Recherches Historiques. 